УДК $630 * 81$

\title{
МИКРОКАЛОРИМЕТРИЯ ЭНТАЛЬПИИ СМАЧИВАНИЯ ДРЕВЕСИНЫ ЛИСТВЕННИЦЫ В ДИМЕТИЛСУЛЬФОКСИДЕ И МЕТИЛЦЕЛЛОЗОЛЬВЕ: ОПРЕДЕЛЕНИЕ СОДЕРЖАНИЯ ЦЕЛЛЮЛОЗЫ, ЛИГНИНА И ЭКСТРАКТИВНЫХ ВЕЩЕСТВ
}

\author{
(C) С.Р. Лоскутов, А.А. Анискина ${ }^{*}$ О.А. Шапченкова
}

Институт леса им. В.Н. Сукачева СО РАН, Академгородок, 50/28, Красноярск, 660036 (Россия), e-mail: aniskina_a@ksc.krasn.ru

В работе рассматривается возможность использования органических растворителей (диметилсульфоксида и метилцеллозольва) в качестве молекулярных зондов для установления взаимосвязи между химическим составом и интегральной теплотой смачивания древесины, определяемой методом дифференциальной микрокалориметрии теплового потока.

Экспериментальные исследования проведены с использованием образцов древесины лиственницы, произрастающей в разных ботанико-географических районах и отличающихся друг от друга содержанием целлюлозы, лигнина и экстрактивных веществ.

Установлены корреляционные связи интегральной теплоты смачивания в ДМСО и МЦ с массовой долей целлюлозы, лигнина и экстрактивных веществ в древесине лиственницы. Так, линейные анаморфозы зависимости теплоты смачивания древесины в метилцеллозольве от содержания в ней целлюлозы, лигнина и экстрактивных веществ характеризуются величинами коэффициента корреляции $0,967,0,846$ и 0,960 соответственно. Для аналогичных зависимостей при использовании в качестве молекулярного зонда диметилсульфоксида значения коэффициента корреляции равны $0,948,0,906$ и 0,955. Это свидетельствует о применимости предлагаемого варианта микрокалориметрии для количественной оценки указанных компонентов древесинного вещества.

Результаты исследования могут представлять интерес, по нашему мнению, как для технологов, занимающихся переработкой древесины, так и для древесиноведов, изучающих влияние природных и антропогенных факторов на показатели свойств древесины. Использование предлагаемого метода, по-видимому, можно распространить и на древесину других пород при соблюдении ряда условий, отмеченных в данной работе.

Ключевые слова: микрокалориметрия, древесина лиственницы, диметилсульфоксид, метилцеллозольв, целлюлоза, лигнин, экстрактивные вещества.

\section{Введение}

Сорбционные свойства древесины по отношению к низкомолекулярным физически активным веществам (НMB) зависят от особенностей строения клеточной стенки, химического состава и надмолекулярной организации древесинного вещества $[1,2]$. Поэтому следует ожидать, что энтальпия взаимодействия древесины с органическими растворителями, обладающими выраженным термодинамическим сродством к ее компонентам, может использоваться для количественной оценки содержания в древесине целлюлозы (в целом углеводного комплекса), лигнина и экстрактивных веществ.

Ранее на основе литературных данных о величинах параметра растворимости целлюлозы, лигнина и пентозанов [3], о химическом составе 355 образцов древесины разных пород из разных ботанико-

Лоскутов Сергей Реджинальдович - заместитель директора, доктор химических наук, тел.: (391)249-44-69, e-mail: 1sr@ksc.krasn.ru

Анискина Антонина Александровна - научный сотрудник, тел.: (391)249-44-69, e-mail: aniskina_a@ksc.krasn.ru Шапченкова Ольга Александровна - научный сотрудник, кандидат биологических наук, тел.: (391)249-44-69, e-mail: sholga@ksc.krasn.ru географических районов [4] был рассчитан параметр растворимости древесинного вещества $\delta_{w s}$ [2] по методу [5].

Оказалось, что $\delta_{w s}$ изменяется в пределах от 25,14 до 26,31 Дж ${ }^{0.5} \cdot \mathrm{cm}^{-1.5}$, т.е. является практически постоянной величиной, в то время как массо-

\footnotetext{
* Автор, с которым следует вести переписку.
} 
вая доля гемицеллюлоз (полиоз), целлюлозы, лигнина и экстрактивных веществ в древесине лиственных пород колеблется в пределах 14,8-28,8; 31,1-64,4; 12,3-25,9; 1,6-20,6\%, в древесине хвойных пород - 5,114,$2 ; 30,1-60,7 ; 22,8-33,8 ; 1,8-28,5 \%$ соответственно [4] ${ }^{1}$.

Из анализа кинетики разбухания древесины в ряде органических растворителей по 2-параметрической модели Колмогорова - Ерофеева (параметр растворимости использованных жидкостей $\delta_{s}$ изменялся от 18,22 до 32,91 Дж ${ }^{0.5} \cdot \mathrm{cm}^{-1.5}$ [7]) было установлено, что при разбухании древесины в диметилсульфоксиде (ДМСО, $\delta_{s}=26,69$ Дж ${ }^{0.5} \cdot \mathrm{cm}^{-1.5}$ ) и метилцеллозольве (МЦ, $\delta_{s}=24,79$ Дж $^{0.5} \cdot \mathrm{cm}^{-1.5}$ ) достигается наименьшая объемная доля неразбухшего древесинного вещества при максимальной величине термодинамического сродства к нему этих растворителей (по параметру n уравнения Колмогорова-Ерофеева). Это наблюдение послужило основанием для выбора МЦ и ДМСО в качестве «молекулярных зондов» для проверки гипотезы о возможности количественной оценки содержания целлюлозы, лигнина и экстрактивных веществ древесины лиственницы на основе результатов микрокалориметрического определения теплоты смачивания в МЦ и ДМСО.

\section{Экспериментальная часть}

Образцы древесины лиственницы в виде дисков толщиной около 3 см были заготовлены в разных ботанико-географических районах: в окрестности п. Хатанга, Эвенкийского стационара Института леса им. В.Н. Сукачева СО РАН (п. Тура), в лесонасаждениях Емельяновского района Красноярского края, по методике, принятой в химии древесины [8]. Из спилов древесины выделяли заболонную и ядровую части в виде пластин толщиной около 1 мм и площадью около $4,5 \mathrm{~cm}^{2}$. Затем требуемое количество материала измельчали в дисковой мельнице и отделяли фракцию с размером частиц 0,5-1,0 мм (отдельно заболонную и ядровую части), с которой были проведены все определения влажности древесины, содержания в ней экстрактивных веществ, целлюлозы и лигнина по методикам, изложенным в [8].

Для микрокалориметрического исследования были отобраны образцы древесины лиственницы с различным содержанием целлюлозы в пределах 39,6-47,2\%.

Наиболее приемлемым методом определения интегральной теплоты смачивания твердых тел (в частности, древесины, целлюлозы и т.п.) является микрокалориметрия [9-15].

Микрокалориметрическое определение интегральной теплоты смачивания древесины в ДМСО и МЦ осуществлялось с помощью микрокалориметра типа Кальве. Чувствительность прибора составляла $2,53 \cdot 10^{-5} \mathrm{BT} / \mathrm{мм} \mathrm{шкалы} \mathrm{регистратора}\left(1,28 \cdot 10^{-4}\right.$ Дж/мм² площади пика тепловыделения); постоянная времени 43,5 с. Калибровка и определение констант микрокалориметра осуществлялись по эффекту Джоуля. Инструментальная погрешность определения теплового эффекта 1,2\%. Все измерения проводились при комнатной температуре $(293 \pm 2) \mathrm{K}$.

Для определения интегральной энтальпии смачивания в растворителе $\left(\Delta \mathrm{H}_{\mathrm{w}}\right)$ были отобраны образцы древесины лиственницы сечением около 1 мм² и длиной 10-15 мм с различным содержанием целлюлозы (см. выше), кондиционированные в гигростатах до постоянной влажности (около 2\%). Масса образца древесины составляла 7-25 мг. Для каждого образца $\Delta \mathrm{H}_{\mathrm{w}}$ измеряли четырехкратно. Методика микрокалориметрических измерений описана ранее в $[12,13]$.

Использованием в качестве смачивающих жидкостей ДМСО и (МЦ) $)^{2}$ достигалось наибольшее воздействие на сетку водородных связей древесинного вещества [13] и разбухание древесины [7], обеспечивающие наилучшее «зондирование» (по энтальпии смачивания) полимерного комплекса древесинного вещества. МЦ - амфотерный растворитель, в силу чего может рассматриваться как «универсальный» для неполимерных компонентов древесинного вещества и, следовательно, наиболее информативный молекулярный зонд по отношению к экстрактивным веществам древесины.

Обработку экспериментальных данных осуществляли с помощью программных средств MO Excel 2007 и TablCurve 2D v. 5.01.

\footnotetext{
${ }^{1}$ Инвариантность $\delta_{w s}$ древесинного вещества относительно «преобразования» ботанико-географических координат происхождения древесины и видовой принадлежности наводит на мысль о существовании некоего закона сохранения. Физический смысл его состоит в постоянстве энергии когезии древесинного вещества (обеспечивающем, в частности, условие (среди прочего) «независимости» механических свойств стволов от видовой принадлежности деревьев и среды произрастания), так как в соответствии с теорией Ван Лаара - Гильдебранда - Скетчарда $[5] \delta_{\mathrm{ws}}=\left(\mathrm{E}_{\mathrm{c}} / \mathrm{v}\right)^{0.5}$, где $\mathrm{E}_{\mathrm{c}}-$ плотность энергии когезии, $\mathrm{v}-$ удельный объем $\left(\approx 0.667 \mathrm{~cm}^{3} \cdot \Gamma^{-1}\right.$ сухого древесинного вещества), следовательно, $\mathrm{E}_{\mathrm{c}}=$ $\mathrm{v} \cdot\left(\delta_{\mathrm{ws}}\right)^{2} \cong$ const $[6]$.

${ }^{2}$ В работе использовали ДМСО и МС квалификации «ч.д.а.»
} 


\section{Обсуждение результатов}

На примере древесины лиственницы установлено, что неоднородность ее химического состава обусловлена комплексом форм изменчивости - климатических и таксационных [16]. Изучение изменчивости химического состава осуществлялось авторами через количественную оценку эффекта воздействия комплекса климатических и таксационных факторов на средние значения показателей химического состава древесины лиственницы: содержания целлюлозы, лигнина, пентозанов, водорастворимых и экстрактивных веществ.

По свидетельству авторов цитируемой работы, проверка информационной способности полученных ими моделей (уравнений регрессии) показала, что все они являются высокоинформативными, а значения прогнозируемых показателей (содержание целлюлозы, лигнина, пентозанов, водорастворимых и экстрактивных веществ) можно считать истинными в пределах диапазона изменения входных параметров.

На базе сопряженного анализа с помощью этих моделей [16] и при наличии сведений о связи содержания основных компонентов древесинного вещества с интегральной теплотой смачивания древесины в НМВ можно было бы расширить возможности экспрессного получения информации о физико-химических характеристиках древесины, заготовленной в разных районах произрастания лесонасаждений, не прибегая к их измерению. Вместе с тем микрокалориметрию с целью оценки химического состава древесины, повидимому, можно рассматривать и как самостоятельный (альтернативный модельному подходу Л.П. Иваняна и А.В. Бейгельмана [16]) метод.

В таблице представлены данные о содержании целлюлозы, лигнина и экстрактивных веществ (включая водорастворимые вещества) в исследованных образцах древесины и результаты микрокалориметрического определения теплоты смачивания в ДМСО и МЦ.

На рисунках 1 и 2 в качестве примера показаны результаты микрокалориметрии смачивания древесины лиственницы в ДМСО и МЦ.

Рисунок 3 иллюстрирует связь теплоты смачивания древесины лиственницы в МЦ и ДМСО с содержанием в ней целлюлозы, лигнина и экстрактивных веществ. Во всех случаях, кроме одного (Qмц $=$ $\mathrm{f}(\mathrm{Ex}))$, зависимость $\mathrm{Q}=\mathrm{f}\left(\mathrm{X}_{\mathrm{i}}\right)$, где $\{\mathrm{Xi}\}=\{\mathrm{C}, \mathrm{L}, \mathrm{Ex}\}$ не является линейной. При этом коэффициент корреляции достаточно высокий, чтобы использовать эти зависимости в практике количественной оценки указанных компонентов древесины.

Теплота смачивания образцов древесины лиственницы с различным содержанием целлюлозы (C), лигнина (L) и экстрактивных веществ (Ех) в метилцеллозольве (МЦ) и диметилсульфоксиде (ДМСО)

\begin{tabular}{c|c|c|c|c|c}
\hline $\begin{array}{c}\text { Образец } \\
\text { древесины }\end{array}$ & $\mathrm{C}, \%$ & $\mathrm{~L}, \%$ & $\mathrm{Ex}, \%$ & $\mathrm{Q}_{\mathrm{MC}}$, Дж·Г ${ }^{-1}$ & $\mathrm{Q}_{\text {дмсо, Дж·г }}{ }^{-1}$ \\
\hline 1 & 39,57 & 26,90 & 17,07 & 3,01 & 13,73 \\
2 & 39,38 & 26,53 & 17,30 & 3,86 & 10,15 \\
3 & 42,88 & 27,02 & 11,36 & 12,16 & 15,40 \\
4 & 44,67 & 28,90 & 5,62 & 14,68 & 24,00 \\
5 & 45,66 & 28,19 & 6,64 & 17,67 & 30,22 \\
6 & 47,17 & 28,64 & 3,76 & 22,65 & 30,97 \\
7 & 45,55 & 28,49 & 4,00 & 24,70 & 33,21 \\
\hline
\end{tabular}
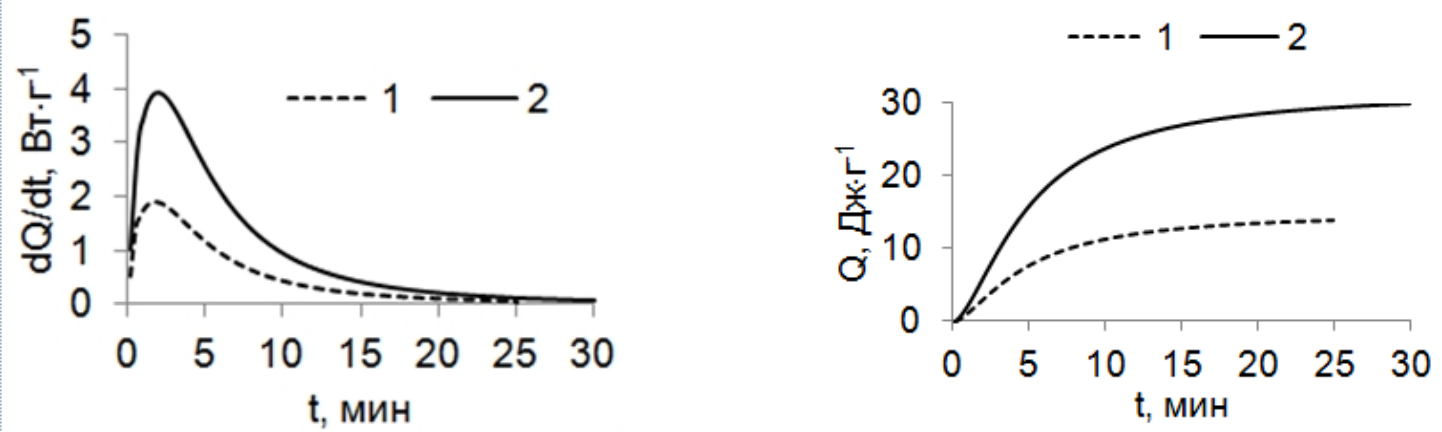

Рис. 1. Термокинетические кривые смачивания древесины лиственницы в ДМСО: 1- древесина ядра; 2 - древесина заболони. Величины тепловой мощности $(\mathrm{dQ} / \mathrm{dt})$ и тепловыделения $(\mathrm{Q})$ рассчитаны на единицу массы сухого вещества (CB) древесины. (Во всех случаях измерения $\Delta \mathrm{H}_{\mathrm{w}}$ взаимодействия древесины с ДМСО и МЦ было экзотермичным. Поэтому здесь и в дальнейшем из соображений удобства изменение энтальпии (- $\left.\Delta \mathrm{H}_{\mathrm{w}}\right)$ заменено на теплоту $(\mathrm{Q})$ смачивания) 

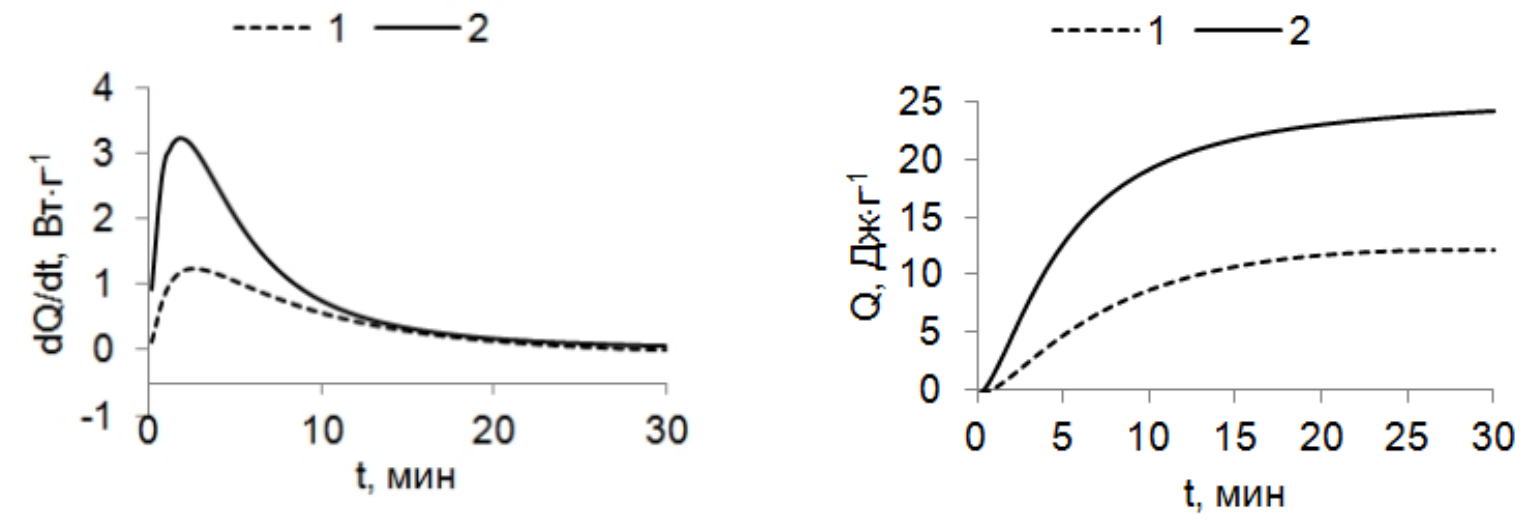

Рис. 2. Термокинетические кривые смачивания древесины лиственницы в МЦ: 1 - древесина ядра; 2 - древесина заболони.
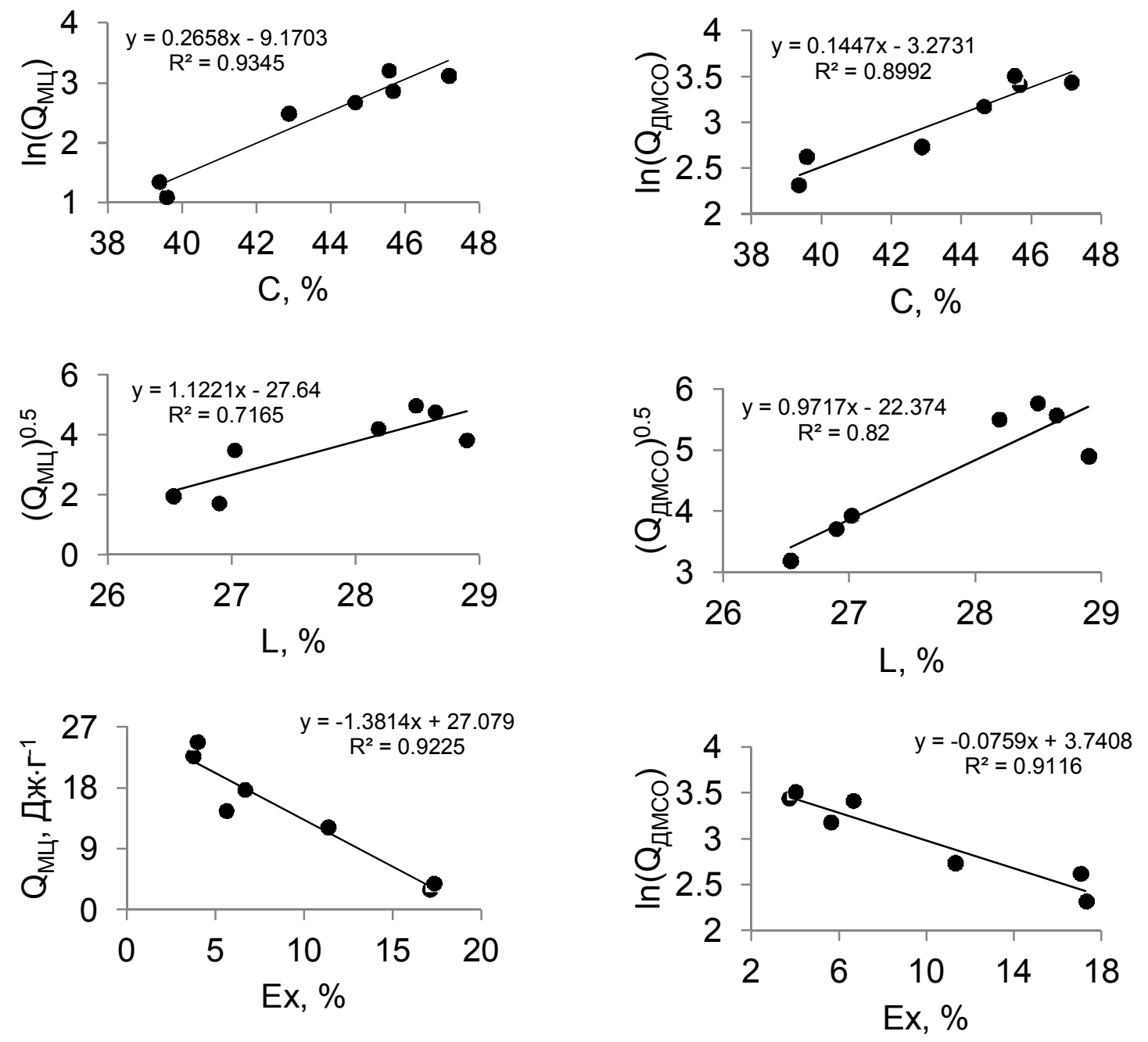

Рис. 3. Линейные анаморфозы связи теплоты смачивания древесины лиственницы в метилцеллозольве

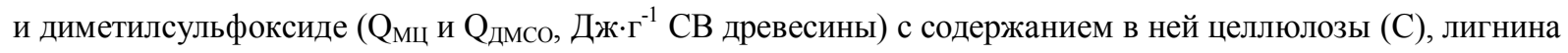
(L) и экстрактивных веществ (Ex) 
Для «работоспособности» этого метода (с использованием МЦ и ДМСО в качестве «молекулярных зондов») в отношении древесины других пород необходимо соблюсти ряд условий.

Во-первых, необходимо снять влияние анатомической специфики древесины той или иной породы, связанной с макрокапиллярным впитыванием растворителя-зонда, что достигается измельчением образца древесины.

Во-вторых, необходимо учитывать пределы суммарного содержания экстрактивных и водорастворимых веществ: при содержании Ех выше 15-17\% тепловой эффект их растворения и сольватации могут в значительной степени или даже полностью компенсировать друг друга, что сделает невозможной количественную оценку компонентов древесины.

Для построения «калибровочных кривых» $\mathrm{Q}_{\text {мц(дмCO) }}=\mathrm{f}(\mathrm{C}, \mathrm{L}, \mathrm{Ex})$ могут быть использованы образцы, отобранные из спилов (дисков) по диаметру и высоте ствола одного-двух стволов данной породы.

Наиболее точным определение содержания в древесине целлюлозы и лигнина в результате микрокалориметрического измерения теплоты смачивания, очевидно, будет при использовании обессмоленных и проэкстрагированных горячей водой [8] образцов. В этом случае тепловой эффект взаимодействия древесинного вещества обусловливается разрушением сетки водородных связей и сольватацией полимерных компонентов, от соотношения которых и будет зависеть суммарный тепловой эффект [13].

Напомним, что все сказанное выше относится к определению теплоты смачивания древесины в МЦ и ДМСО. При использовании других растворителей картина взаимодействия их с древесиной существенно иная $[2,13,17]$.

\section{Выводы}

Резюмируя, отметим, что изложенные здесь результаты исследования свидетельствуют о возможности использования микрокалориметрии смачивания древесины лиственницы в МС и ДМСО для экспрессной оценки содержания в ней целлюлозы, лигнина и экстрактивных веществ, включая водорастворимые соединения. Эта информация в совокупности с данными термического анализа древесины [18, 19] и сведениями об условиях среды обитания древесных растений может представлять интерес, по нашему мнению, как для технологов, занимающихся переработкой древесины, так и для древесиноведов, изучающих влияние природных и антропогенных факторов на показатели свойств древесины. Использование предлагаемого метода, по-видимому, можно распространить и на древесину других пород при соблюдении отмеченных выше условий.

\section{Список литературы}

1. Лоскутов С.Р., Анискина А.А., Пермякова Г.В., Миронов П.В. Способ определения реакции растущего дерева на внешние условия // Строение, свойства и качество древесины: труды II Международного симпозиума. М., 1997. С. 92-95.

2. Лоскутов С.Р. Взаимодействие древесины с физически активными низкомолекулярными веществами. Новосибирск, 2004. $171 \mathrm{c.}$

3. Скребец Т.Э., Боголицин К.Г., Гурьев А.Ю. Термодинамическая совместимость компонентов древесины // Химия древесины. 1992. №4-5. С. 3-4.

4. Fengel D., Grosser D. Chemische Zusammensetzung von Nadel- und Laubhölzern // HOLZ als Roh- und Werkstoff. 1975. Vol. 33, N1. Pp. 32-34.

5. Rebenfeld L., Makarewicz P.J., Weigman H.-D., Wilkes G.L. Interaction between solvents and polymers in the solid state // J. Macromol. Sci. - Rev. Macromol. Chem. 1976. Vol. 15C, N2. Pp. 279-393.

6. Loskutov S.R., Tyutkova E.A. The invariance some physico-chemical properties of wood // Fundamental science and technology - promising developments. CreateSpace, North Charlestone, SC, USA, 2013. Vol. 2. Pp. 231-235.

7. Loskutov S.R., Aniskina A.A. Swelling of larch wood in organic liquids // Holzforshung. 2008. Vol. 62, N3. Pp. 357-361.

8. Оболенская А.В., Ельницкая 3.П., Леонович А.А. Лабораторные работы по химии древесины и целлюлозы. M., $1991.320 \mathrm{c}$.

9. Кальве Э., Прат А. Микрокалориметрия. М., 1963. 477 с.

10. Hossfeld R.L. The effect of degree of swelling of wood on its permeability toliquids // Holzforschung. 1972. Vol. 26, N2. Pp. 70-76.

11. Johns W.E., Miller W.G., Hossfeld R.L. A thermodynamic comparison of the adsorption of binary liquid and vapor on northern cedar sapwood // Holzforschung. 1974. Vol. 28, N3. Pp. 82-85.

12. Лоскутов С.Р., Штаб О.И. Взаимодействие в системе древесина-вода-диметилсульфоксид // Химия древесины. 1991. №1. С. 17-25.

13. Loskutov S.R. Effect of organic solvent on wood substance matrix hydrogen bond structure // Holzforschung. 1997. Vol. 51, N4. Pp. 369-371. 
14. Wadsö I., Goldberg R.N. Standards in isothermal microcalorimetry (IUPAC Technical Report) // Pure Appl. Chem. 2001. Vol. 73, N10. Pp. 1625-1639.

15. Ioelovich M. Heat effect of interaction between cellulose and various polar liquids // SITA. 2011. Vol. 13, N1. P. 35-44.

16. Иванян Л.П., Бейгельман А.В. Изменчивость химических свойств древесины лиственницы, произрастающей в Сибири и на Дальнем Востоке // Химия древесины. 1984. №2. С. 15-18.

17. Hansen C.M., Björkman A. The ultrastructure of wood from a solubility parameter poin of view // Holzforschung. 1990. Vol. 52, N4. Pp. 335-344.

18. Лоскутов С.Р., Тютькова Е.А. Термогравиметрия древесины индивидуальных годичных слоев лиственницы (Larix gmelinii Rupr.) // Строение, свойства и качество древесины - 2014 : материалы V Международного симпозиума. М.; Мытищи, 2014. С. 104-108.

19. Лоскутов С.Р., Анискина А.А. Термический анализ древесины основных лесообразующих пород Сибири // Лесные биогеоценозы бореальной зоны: география, структура, функции, динамика : материалы Всероссийской научной конференции с международным участием, посвященной 70-летию создания Института леса им. В.Н. Сукачева СО РАН. Новосибирск, 2014. С. 22-26.

Поступило в редакцию 15 июня 2015 г.

После переработки 18 ноября 2015 2. 
Loskutov S.R., Aniskina A.A. ${ }^{*}$, Shapchenkova O.A. THE MICROCALORIMETRY OF ENTHALPY OF LARCH WOOD WETTING IN DIMETHYL SULFOXIDE AND METHYLCELLOSOLVE: DETERMINATION OF CELLULOSE, LIGNIN AND EXTRACTIVES

V.N. Sukachev Institute of Forest SB RAS, Akademgorodok, 50/28, Krasnoyarsk, 660036 (Russia),

e-mail: aniskina_a@ksc.krasn.ru

The possibility of application of organic solvents (dimethyl sulfoxide and methylcellosolve) as molecular probes for establishing relationship between chemical composition and integrated enthalpy of wood wetting determined by method of differential microcalorimetry of heat flow has been studied in this work.

The samples of larch wood from different botanico-geographic regions were used in the experiments. The samples were also different from each other in contents of cellulose, lignin, and extractives.

The correlations between integral heat of wetting in dimethyl sulfoxide and methylcellosolve and contents of cellulose, lignin, and extractives in larch wood were detected. So, linear anamorphoses of relationship between heat of wood wetting in methylcellosolve and contents of cellulose, lignin, and extractives in wood were characterized by correlation coefficients of $0.967,0.846$, and 0.960 , respectively. The correlation coefficients were found to be $0.948,0.906$, and 0.955 when dimethyl sulfoxide has been used as molecular probe. These results indicate that the proposed variant of microcalorimetry can be used for quantitative estimation of wood components.

In our opinion, the research results would be useful for wood technologists as well as wood scientists studying the influence natural and anthropogenic factors on wood properties. The method proposed in this paper can be applied to other wood species under the conditions of the experiments.

Keywords: microcalorimetry, larch wood, dimethyl sulfoxide, methylcellosolve, cellulose, lignin, extractives.

\section{References}

1. Loskutov S.R., Aniskina A.A., Permiakova G.V., Mironov P.V. Stroenie, svoistva i kachestvo drevesiny: trudy II Mezhdunarodnogo simpoziuma. [Structure, properties and quality of the wood: the works of the VII International Symposium]. Moscow, 1997, pp. 92-95. (in Russ.).

2. Loskutov S.R. Vzaimodeistvie drevesiny s fizicheski aktivnymi nizkomolekuliarnymi veshchestvami. [Interaction with the timber physically active low molecular weight substances]. Novosibirsk, 2004, 171 p. (in Russ.)

3. Skrebets T.E., Bogolitsin K.G., Gur'ev A.Iu. Khimiia drevesiny, 1992, no. 4-5, pp. 3-4. (in Russ.).

4. Fengel D., Grosser D. Holz als Roh- und Werkstoff, 1975, vol. 33, no. 1, pp. 32-34.

5. Rebenfeld L., Makarewicz P.J., Weigman H.-D., Wilkes G.L. J. Macromol. Sci. - Rev. Macromol. Chem., 1976, vol. 15 C, no. 2, pp. 279-393.

6. Loskutov S.R., Tyutkova E.A. Fundamental science and technology - promising developments. CreateSpace, North Charlestone, SC, USA, 2013, vol. 2, pp. 231-235.

7. Loskutov S.R., Aniskina A.A. Holzforshung, 2008, vol. 62, no. 3, pp. 357-361.

8. Obolenskaia A.V., El'nitskaia Z.P., Leonovich A.A. Laboratornye raboty po khimii drevesiny $i$ tselliulozy. [Laboratory work on the chemistry of wood and cellulose]. Moscow, 1991, 320 p. (in Russ.).

9. Kal've E., Prat A. Mikrokalorimetriia. [Microcalorimeters]. Moscow, 1963, 477 p. (in Russ.).

10. Hossfeld R.L. Holzforschung, 1972, vol. 26, no. 2, pp. 70-76.

11. Johns W.E., Miller W.G., Hossfeld R.L. Holzforschung, 1974, vol. 28, no. 3, pp. 82-85.

12. Loskutov S.R., Shtab O.I. Khimiia drevesiny, 1991, no. 1, pp. 17-25. (in Russ.).

13. Loskutov S.R. Holzforschung, 1997, vol. 51, no. 4, pp. 369-371.

14. Wadsö I., Goldberg R.N. Pure Appl. Chem., 2001, vol. 73, no. 10, pp. 1625-1639.

15. Ioelovich M. SITA, 2011, vol. 13, no. 1, pp. 35-44.

16. Ivanian L.P., Beigel'man A.V. Khimiia drevesiny, 1984, no. 2, pp. 15-18. (in Russ.).

17. Hansen C.M., Björkman A. Holzforschung, 1990, vol. 52, no. 4, pp. 335-344.

18. Loskutov S.R., Tiut'kova E.A. Stroenie, svoistva i kachestvo drevesiny - 2014 : materialy V Mezhdunarodnogo simpoziuma [Structure, properties and quality of wood - 2014: Proceedings of the V International Symposium]. Moscow; Mytishchi, 2014, pp. 104-108. (in Russ.).

19. Loskutov S.R., Aniskina A.A. Lesnye biogeotsenozy boreal'noi zony: geografiia, struktura, funktsii, dina-mika : materialy Vserossiiskoi nauchnoi konferentsii s mezhdunarodnym uchastiem, posviashchennoi 70-letiiu sozdaniia Instituta lesa im. V.N. Sukacheva SO RAN. [Boreal forest ecosystems: geography, structure, function, dynamics: Proceedings of the Scientific Conference with international participation, dedicated to the 70th anniversary of the V.N. Sukachev Institute of Forest SB RAS]. Novosibirsk, 2014, pp. 22-26. (in Russ.).

Received Juny 15, 2015

Revised November 18, 2015

\footnotetext{
* Corresponding author.
} 
